\title{
Cogging Torque Reduction Technique on E-Core Hybrid Flux Switching Motor by Notching and Pole Pairing
}

\author{
Jaudah Abd Rani ${ }^{1}$, Erwan Sulaiman ${ }^{2}$, Md Zarafi Ahmad ${ }^{3}$, Mohd Fairoz Omar ${ }^{4}$, \\ Chockalingam Aravind Vaithilingam ${ }^{5}$ \\ ${ }^{1,2,3,4}$ Research Center For Applied Electromagnetics, Universiti Tun Hussein Onn Malaysia, Malaysia \\ ${ }^{5}$ School of Engineering, Taylors University, Malaysia
}

\section{Article Info}

Article history:

Received Dec 21, 2017

Revised Jan 22, 2018

Accepted Feb 7, 2018

\section{Keyword:}

Chamfering

Cogging torque

HFSM

Notching

Pole pairing

\begin{abstract}
In the past, 4S-10P E-Core Hybrid Flux Switching Motor (HFSM) had been studied. However, the motor suffers high cogging torque but it has high performance in terms of high power and high torque at high speed. Therefore, this paper is proposing the cogging torque reduction techniques to minimize the cogging torque. The high cogging torque gave an undesirable effect during low operating speed of the motor. In order to tackle the issue, the cogging torque mechanism in equation is laid out as a form of reference. Then the reduction techniques employed on the designs and analyzed with Finite Element analysis (FEA) in JMAG. The results show the cogging torque of the optimized design is $44.45 \%$ of the motor torque. Besides, the techniques employed to identify which techniques gave the most cogging torque reduction and analyzed the geometrical difference using the cogging torque mechanism. Finally, the analysis is discussed based on the modified geometrics.
\end{abstract}

Copyright (c) 2018 Institute of Advanced Engineering and Science. All rights reserved.

\section{Corresponding Author:}

Jaudah Abd Rani,

Research Center For Applied Electromagnetics,

Universiti Tun Hussein Onn Malaysia,

86400 Parit Raja, Batu Pahat, Johor, Malaysia

Email: he1500@siswa.uthm.edu.my

\section{INTRODUCTION}

The merits of Hybrid Flux Switching Motor (HFSM) had increased along with some studies conducted on HFSM structure, operation, and performance such as high torque density, high power density, and high efficiency. In [1] stated that flux switching motor has higher torque density compared to the fluxreversal motor and the doubly salient pole motor due to the employment of the flux focusing effect, back electromotive force (back-emf) and the bipolar flux linkage of the motor. The research also investigates the air-gap variation for the requirement of certain electrical machine application, as the magnetic field on the medium of air is part of the working principle of the machine. Another significant advantage of HFSM is the trade-off usage of rare magnets substituted with field excitation windings as proposed in [2]. Given a constants specification with the source of magnetomotive force (MMF) at manipulative variable, HFSM may overcome the obstacle of keeping high power density motor with the lesser usage of rare magnets by replacing the reduced weight of rare magnets with field excitation windings made of copper. Apart from that, the magnetic source such that field excitation windings result in another advantage of controlling the magnetic flux capability which is very useful in speed control [2][3].

In Figure 1, a HFSM having 4 stator slots and 10 rotor poles is illustrated as the slot pole studies was investigated in [4] and the slot windings combination is proposed in Figure 2. The operating principles of the HFSM are shown in Figure 3 where the term hybrid is realized by the magnetic source from the 
permanent magnet and the field excitation windings function. The polarity and the applied field currents on armature field windings gave the advantage of strengthening and weakening of the air gap flux density.

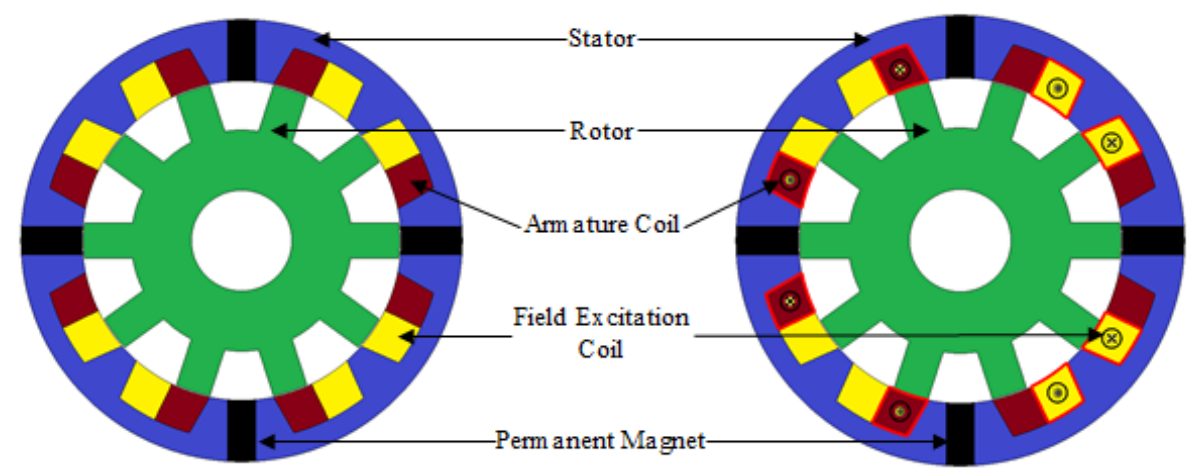

Figure 1. 4S-10P E-Core HFSM

Figure 2. 4S-10P HFSM coil arrangement

The numbers of stator topologies proposed in literature had been mounting such as a conventional stator, E-core [5]-[7], multi-tooth [8], [9] and the advantages of the E-core structure in speed variation for flux weakening performance [10]. The torque and power speed characteristics were studied and compared for the stator topologies type conventional, E-core and C-core in [11]. The E-core proved the superiority in fluxweakening region as high power was constantly achievable over the entire flux-weakening region. In [10] Ecore stator was matched against conventional stator to study the effects of the structural differential on the MMF harmonics and the mutual couplings of the windings.

The pulsating torque generated due to torque ripple and cogging torque is very harmful to all electric motor. As the torque components in the motor are made up mutual torque, reluctance torque, and cogging torque whereas average torque is the main component of the torque. Average torque is defined as the torque produced due to the fundamental stator MMF and magnetic field on the motor [12]. The undesired torque ripple originated from the mutual interactions between the stator MMF harmonics and the magnetic field of the motor. The distinct complications resulted from the torque ripple is the noise and vibration transpire at low speed. As the torque ripples substantiate the effects at low speed at the same time, the system inertia eliminates the torque pulsations at higher speeds. Besides that, the diminishing component of torque such that cogging torque is arising by the alternate interrelation between the magnetic field and stator slot or air gap reluctance variation. Ideally, the average cogging torque must be zero for the variation shows insignificant coil excitation at the stator.

Much cogging torque reduction techniques had been adopted for flux switching motor design such as permanent magnet flux switching motor [12]-[16]. As the past research had shown, the minimization technique can be divided into two category which is the control type minimization and design type minimization on which this paper is adopting [17], [18]. The design type minimization extrapolates varieties of techniques that can be dominated to best fit the design as each of the motor designs are exclusively subjected to certain constraints and necessities. Such techniques are stator, rotor and magnet skewing, dummy poles, chamfering, and notching.

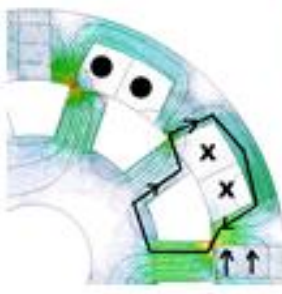

(a)

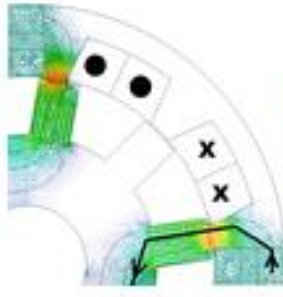

(b)

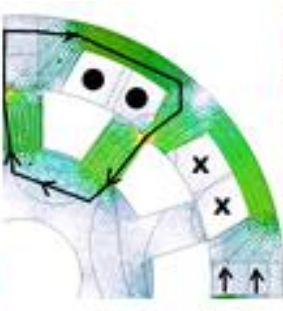

(c)

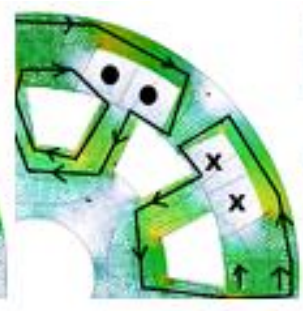

(d)

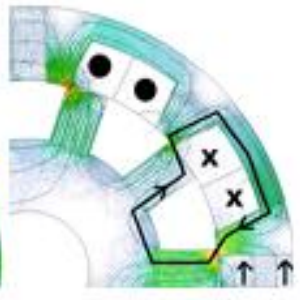

(e)

Figure 3. Operational principle of (a) and (b) demagnetization as well as (c), (d) and (e) magnetization of 4S10P E-Core HFSM 
Among the many research had been conducted to search for the excellent technique on the motor, most of the research focused on permanent magnet type motor as the permanent magnet type motor often faced huge manufacturing cost to achieve optimum performance regarding the designs. Hence, it leaves a gap on the reduction technique adopted for HFSM as HFSM and permanent magnet flux switching motor is varied relating to the source of flux and influence of the flux generated by the torque.

This paper concentrates on the variation of techniques that can be adopted for two-dimensional design (2D) of 4S-10P E-Core HFSM to diminish as minimal as possible the cogging torque. In [19] (cite paper IRIS), the design of 4S-10P E-Core HFSM had been optimized but it suffers high peak value of cogging torque at $108.45 \mathrm{Nm}$. The diversify notching and pole pairing techniques proposed which hypothetically will influence the cogging torque along with the discussion of it. The introduction of cogging torque mechanism is to clarify the operating principle of the reduction technique and justify it as effective approaches. The paper illustrates the equation as tools to justify the appropriate techniques to be enforced on the said design by the objective of lower cogging torque.

\section{COGGING TORQUE MECHANISM}

The Fourier series may define cogging torque determined by finite element method. The cogging torque derived from the production of torque [20]. The production of torque is derived from the differential of energy against time as per described in (1).

$$
P_{m}=\frac{d W_{m}}{d t}=T \frac{d \theta}{d t}=T w
$$

$P_{m}$ is the motor power, $d W_{m}$ is the differential energy of motor, $d \theta$ is the differential mechanical angle, $w$ is the angular velocity and $T$ is the torque. Torque of the motor consistently composed of reluctance torque, alignment torque and cogging torque expressed in (2).

$$
\begin{gathered}
T=T_{R}+T_{A}+T_{\operatorname{cog}} \\
T_{R}=\frac{1}{2} i^{2} \frac{d L}{d \theta} \\
T_{A}=N i \frac{d \emptyset_{g}}{d \theta} \\
T_{\operatorname{cog}}=-\frac{1}{2}\left(\emptyset_{g}\right)^{2} \frac{d R}{d \theta}
\end{gathered}
$$

In (2), $T$ is torque, $T_{R}$ is reluctance torque and $T_{\operatorname{cog}}$ is cogging torque. Subsequently, the derivation of $T_{R}, T_{A}$ and $T_{c o g}$ results in $\emptyset_{g}$, air gap flux, $d R$ is the air gap reluctance and $d \theta$ is the rotor position. From the derivation it clearly shown the cogging torque existence originated from the interaction of the magnet producing air gap flux between the stator and the rotor in variable with the air gap reluctance with time.

The periodic changes in the cogging torque also contributed by the corresponding EMF harmonics of the magnets and the stator magnetic conductance due to air gap reluctance changes periodically. The periodic changes in the cogging torque can be evaluated with Fourier series expressed in (6).

$$
T_{c o g}\left(\theta_{m}\right)=\sum_{n=1}^{\infty} T_{n} \sin \left(k N_{e} \theta_{m}+\theta_{n}\right)
$$

In (6), $\theta_{m}$ is the rotor angular position, $T_{n}$ is the amplitude of the $\mathrm{n}$-th harmonic, $\theta_{n}$ is the phase angle of the n-th harmonic and $N_{e}$ is the smallest common multiple of rotor pole and stator pole. The numerical equations of air gap flux in (5) can be expressed as in (7).

$$
\begin{aligned}
& B_{r l}(\theta) \\
& \left.=\sum_{k=1,3,5 . .}^{\infty} 2 \frac{\mu_{0} M_{k}}{\mu_{r}} \frac{k p}{(k p)^{2}-1}\left(\frac{R_{m}}{R_{s}}\right)^{k p+1}\left[\frac{(k p-1)+2\left(\frac{R_{m}}{R_{s}}\right)^{k p+1}-(k p+1)\left(\frac{R_{m}}{R_{s}}\right)^{2 k p}}{\frac{\mu_{r}+1}{\mu_{r}}\left[1-\left(\frac{R_{r}}{R_{s}}\right)^{2 k p}\right]-\frac{\mu_{r}-1}{\mu_{r}}\left[\left(\frac{R_{m}}{R_{s}}\right)^{2 k p}-\left(\frac{R_{r}}{R_{m}}\right)^{2 k p}\right] \cos k p \theta}\right]\right]
\end{aligned}
$$




$$
\begin{aligned}
& M_{k}=2\left(\frac{B_{r}}{\mu_{0}}\right) \alpha_{p} \frac{\sin \left(\frac{n \pi \alpha_{p}}{2}\right)}{\left(\frac{n \pi \alpha_{p}}{2}\right)} \\
& \emptyset_{g}=\alpha B_{r l}\left(\theta_{m}\right) \frac{\pi}{p}\left(R_{m}^{2}-R_{m i}^{2}\right)
\end{aligned}
$$

Where $R_{m}$ is the outer radius of the magnet, $R_{s}$ is the outer radius of the stator, $R_{r}$ is the outer radius of the rotor, $p$ is the pole pairing number, $\alpha_{p}$ is the pole step and $\alpha$ is the coefficient of the magnetic flux density. Since the topologies for 4S-10P E-core HFSM construction possess the same magnitude of outer radius of the magnet and stator. Thus, (7) is derived as (10).

$$
B_{r l}(\theta)=\sum_{k=1,3,5 . .}^{\infty} 2 \frac{\mu_{0} M_{k}}{\mu_{r}} \frac{k p}{(k p)^{2}-1}\left[\frac{(k p-1)+2-(k p+1)}{\frac{\mu_{r}+1}{\mu_{r}}\left[1-\left(\frac{R_{r}}{R_{s}}\right)^{2 k p}\right]-\frac{\mu_{r}-1}{\mu_{r}}\left[1-\left(\frac{R_{r}}{R_{m}}\right)^{2 k p}\right]}\right] \cos k p \theta
$$

\section{4S-10P E-CORE HFSM PARAMETER}

The designs adopted for this analysis is 4S-10P E-Core HFSM which consists of 4 stator slots and 10 rotor poles with the stator slot type E-Core due to the shape of it. The symmetrical shape of the stator allows maximum flux linkage over the full electric cycle [21]. The geometry of the 4S-10P E-Core HFSM discussed in this paper is as shown in Figure 1, the design specification is as illustrated in Table 1.

Table 1. Design specification

\begin{tabular}{lc}
\hline \multicolumn{1}{c}{ Specification } & Value \\
\hline Rotor poles & 10 \\
Air gap (mm) & 0.8 \\
Number of phases & 1 \\
Maximum DC voltage (V) & 50 \\
Maximum current (Arms) & 360 \\
Maximum speed (r/min) & 12000 \\
Air gap (mm) & 0.8 \\
Motor stack length (mm) & 70 \\
Field winding turn & 271 \\
Armature turn & 37 \\
Rotor pole radius (mm) & 86 \\
Rotor core radius (mm) & 61 \\
\hline
\end{tabular}

\section{COGGING TORQUE REDUCTION TECHNIQUE}

In this paper, the reduction techniques enforced on the modeled design of 4S-10P E-Core HFSM are notching, chamfering and rotor pole pairing. The reduction techniques will influence the geometrical design on the rotor only as it easier to be conducted there compared to the stator. If the techniques were to influence the stator parts of this particular design of 4S-10P E-Core HFSM, it would influence other parameters which needed to be kept constant such as permanent magnets, field excitation slot areas, and armature coil slot areas. Hypothetically, it may lead to major changes in the performance on which substantially deviate from the objective of this paper.

The cogging torque reduction technique employed for this paper is shown in Figure 4 are investigated to study the geometrical of the rotor tooth on the cogging torque as well as well as the backEMF and the torque with 2D finite element analysis (FEA). Figure 4. (a) is notching where the parameter established here are a number of the notch, width, and length of each notch. The parameters will evolve by Equation 5 where the air gap reluctance in between the rotor poles and the permanent magnets and stator develops. Figure 4. (b) is rotor 


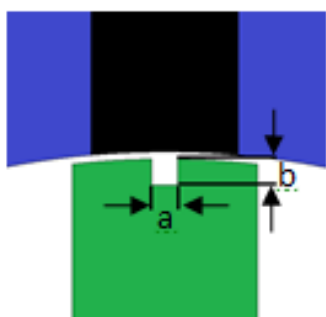

(a)

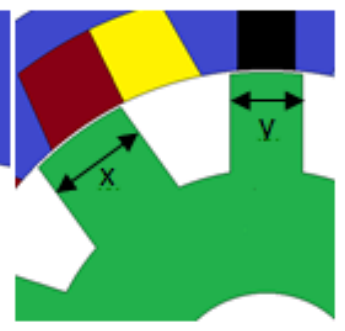

(b)

Figure 4. Type of reduction technique on rotor type (a) notching (b) pole pairing

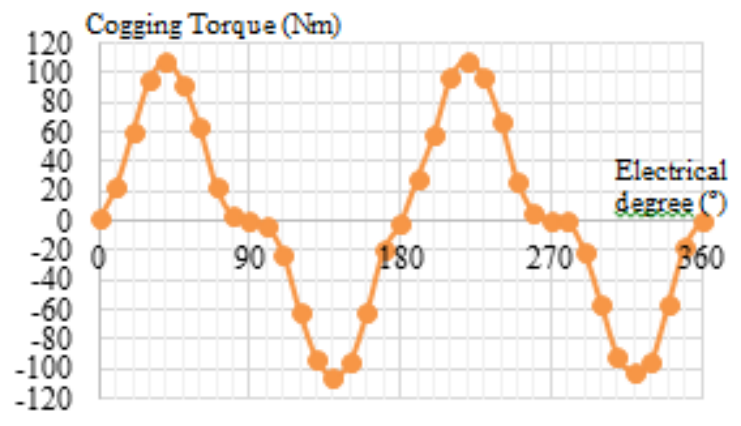

Figure 5. Cogging torque of 4S-10P topology

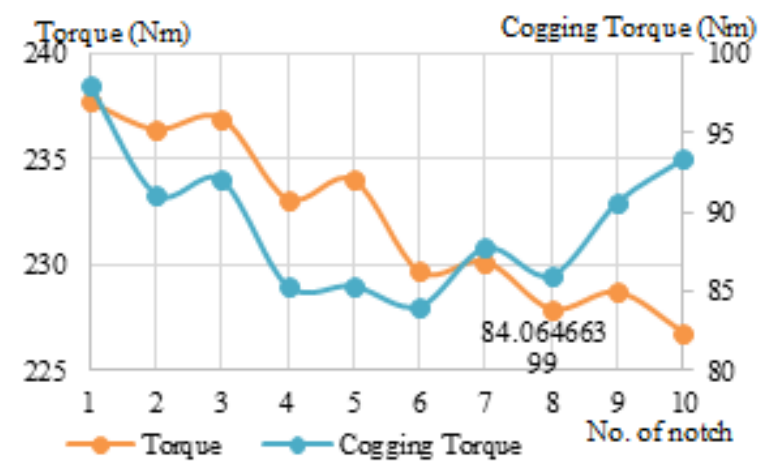

Figure 6. Influence of the notch number on the torque

pole pairing with two parameters such that original rotor width, $\mathrm{y}$ and dummy width, $\mathrm{x}$ which alternately switched to determine the best pair of rotor pole pairing.

The 2D-FEA shows the topology 4S-10P E-Core HFSM possess average cogging torque of $1.38 \mathrm{Nm}$ and peak-to-peak cogging torque of $108.45 \mathrm{Nm}$, shown in Figure 5. Based on Equation (2) it can be inferred the cogging torque, and the electromagnetic torque will be either increase or decrease as both preferences are subjected to the geometrical of the rotor represented as air-gap production over time.

\subsection{Notching}

The influence of parameters such as a number of the notch on cogging torque and the output torque is investigated with 2D-FEA shown in Figure 6. Figure 6 shows the cogging torque decrease from $98 \mathrm{Nm}$ of peak-to-peak cogging torque value with increasing number of the notch with reversing pattern after the $6^{\text {th }}$ notch. The $6^{\text {th }}$ notch recorded the lowest cogging torque achieved at $84 \mathrm{Nm}$. Generally, in each decrement and increments fluctuates with one another. However, the constant decrement of stair pattern can be observed on the output torque as it started at $237 \mathrm{Nm}$ on the first notch and going down to $226 \mathrm{Nm}$ on the $10^{\text {th }}$ notch. The minimization of the cogging torque effectively explained by the decreasing air gap flux. Figure 7 and Figure 8 shows the flux lines and flux vectors before and after notching, respectively. The flux lines in both figures approximately illustrated same concentrations of flux lines however the magnetic flux magnified by the flux vectors distinguished the effect of notching of the 6th notch, which is the lowest cogging torque reduced. The maximum magnetic flux after notching is $3.6 \mathrm{~T}$ while before notching is $3.0 \mathrm{~T}$ on Figure 7 . (b) and Figure 8 (b), respectively. However, the concentration of maximum vector before notching is higher compared to after notching. The vector differential shows the air-gap flux is increasing with notching. Ideally, the air-gap flux inversely proportional to the magnetic flux density subjected to the permanent magnet grades [22]. However, in this case, based on (9), the magnetic flux density coefficient, $\alpha$ is directly proportional to the air gap flux, $B_{r l}$. Thus, the magnetic flux density increase as the air gap flux increase.

Further investigation conducted to investigate the significant influences of width and height of notch on the cogging torque where all parameters are kept constant except for the width and height of the notch. Figure 9 and Figure 10 show the peak-to-peak cogging torque on the notch width at various notch height and the output torque on the notch width at various notch height, respectively. By running the FEA against various notch width and height, the cogging torque significantly reduces with the increasing notch width and increasing notch height. The same observation can be seen with the output torque where it decreases with increasing notch width and notch height in Figure 10. The variation factor can explain the reduction of 
cogging torque. The variation amplitude decrease as well as the variation periods with the increasing size of notch and number of notches which in turns reduced the peak value of cogging torque.

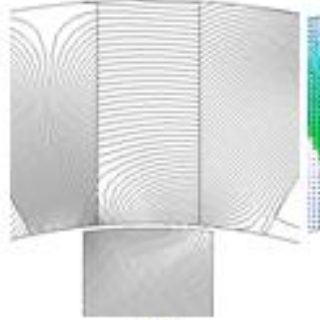

(a)

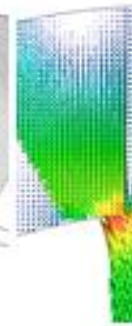

(b)

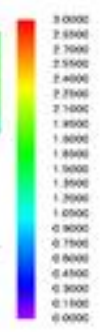

)

Figure 7: Flux lines and flux vectors before notching

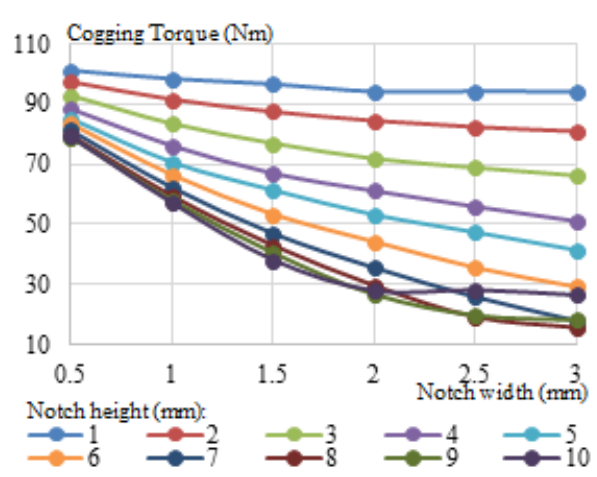

Figure 9. The peak-to-peak cogging torque on the notch

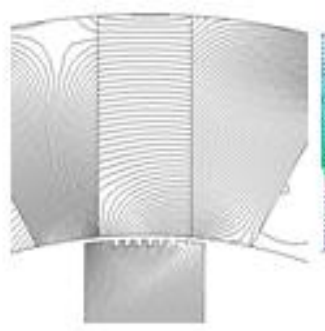

(a)

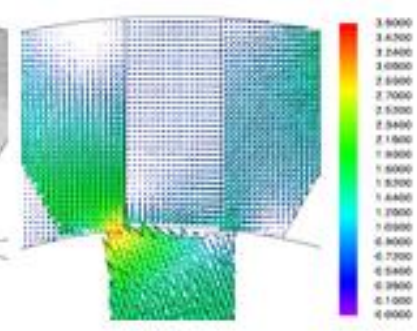

(b)
Figure 8: Flux lines and flux vectors after notching

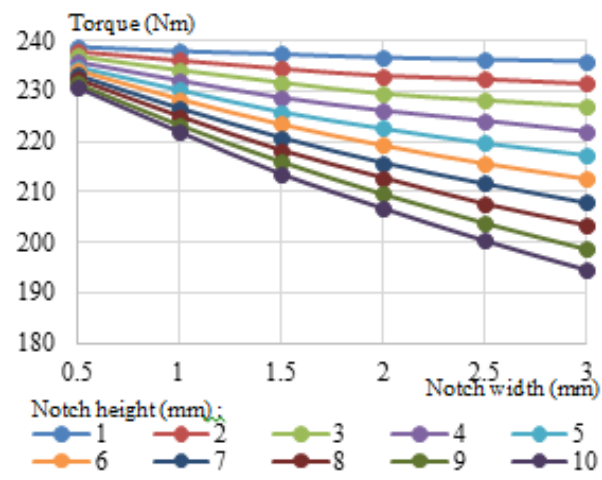

Figure 10. The output torque on the notch width

\subsection{Pole Pairing}

In pole pairing type for cogging torque reduction technique is pairing two different widths of rotor pole geometrically. Since $4 \mathrm{~S}-10 \mathrm{P}$ has an even number of rotor pole, the pairing will alternate between the manipulative pole and the pole which the width is kept constant in its original width. For example, in Figure 4. (b) the manipulative pole which acts as dummy pole marked with unknown $\mathrm{x}$ is for the first pole while the pole which the width is kept constant is characterized with unknown y is from the second pole. After the first cycle of analysis of cogging torque obtains with FEA, the unknown $\mathrm{x}$ and unknown $\mathrm{y}$ are reversed with the first pole and second pole where the first pole is marked with unknown y and the first pole is marked with unknown $\mathrm{x}$.

Figure 11 shows the result of alternating the $\mathrm{x}$ pole and y pole on the first cycle and second cycle. It is evident the torque production increase as the dummy pole width increased from $2 \mathrm{~mm}$ to $50 \mathrm{~mm}$. The maximum output torque of $242 \mathrm{Nm}$ is when the dummy pole width is $10 \mathrm{~mm}$, approximately same as the constant pole at $10.55 \mathrm{~mm}$. The graph pattern for both cycles is same on the same value of increment and decrement, but the cogging torque graph pattern is vice versa. The cogging torque graph for both cycles possesses the same pattern of dropping ping pong ball. In the range between $2 \mathrm{~mm}$ and $50 \mathrm{~mm}$ it has two peaks of cogging torque for in each cycle both at $7 \mathrm{~mm}$ and $42 \mathrm{~mm}$ width of rotor pole. The first peak in the first and second cycle cogging torque peak value are $162 \mathrm{Nm}$ and $153 \mathrm{Nm}$, respectively. The second peak in the first and second cycle cogging torque peak value are $49 \mathrm{Nm}$ and $43 \mathrm{Nm}$, respectively. Comparatively, the highest output torque of $242 \mathrm{Nm}$ in the first and second cycle is same, but the cogging torque in both of the cycle are discriminately different. The second cycle has lower cogging torque compared to the first cycle which is $127 \mathrm{Nm}$ and $139 \mathrm{Nm}$, respectively. The two cycle of alternate change of dummy pole width due to identifying the proper width ratio of rotor pole to the magnet pole. The air gap magnetic resistance was also influenced by the amplitude of the cogging torque. 


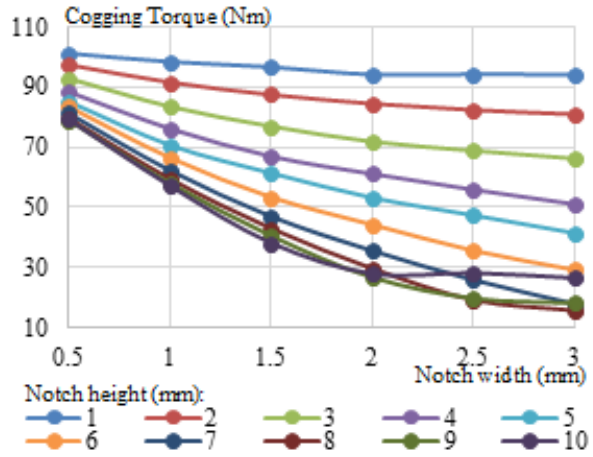

Figure 9. The peak-to-peak cogging torque on the notch

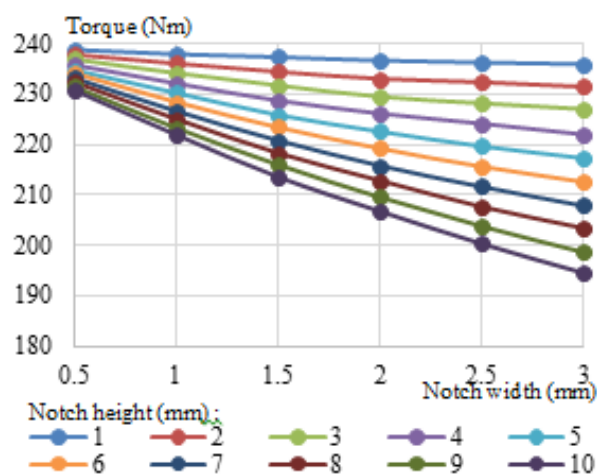

Figure 10. The output torque on the notch width

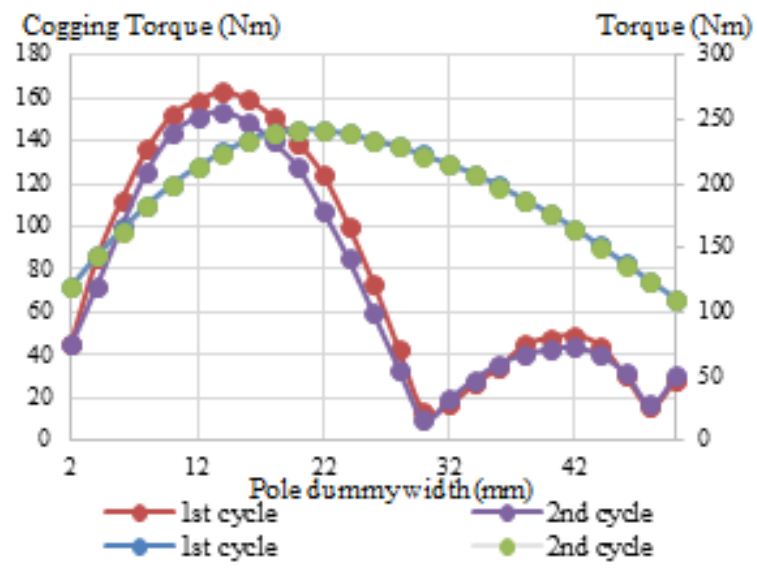

Figure 11. Effect of alternate pole dummy width against

\section{CONCLUSION}

This paper investigated and studied the proposed cogging torque reduction technique variations on 4S-10P E-Core HFSM based on 2D FEA using J-MAG software. The reduction technique adopted was the classical techniques such as notching and pole pairing. Both techniques provided a significant decrease in the cogging torque which fulfill the objective. However, as the cogging torque reduce the output torque reduce as well. Therefore, further study to improve the torque performance needs and in the same time reduce the cogging torque to be carried in the future study.

\section{ACKNOWLEDGEMENT}

This work is funded by Research Innovation, Commercialization and Consultancy management (ORICC), Universiti Tun Hussein Onn Malaysia (UTHM) with Vot. No. U683 and Ministry of Education Malaysia (MOE).

\section{REFERENCES}

[1] A. Lindner and I. Hahn, "Investigation of a large air-gap E-core flux-switching machine with arbitrary magnet shape and grain-oriented material," Proc. - 2016 22nd Int. Conf. Electr. Mach. ICEM 2016, pp. 2445-2451, 2016.

[2] Z. Q. Zhu, "Switched flux permanent magnet machines - Innovation continues," 2011 Int. Conf. Electr. Mach. Syst. ICEMS 2011, no. c, 2011.

[3] J. X. Shen and W. Z. Fei, "Permanent magnet flux switching machines - Topologies, analysis and optimization," Int. Conf. Power Eng. Energy Electr. Drives, vol. 5, pp. 352-366, 2013.

[4] A. Rani, E. Sulaiman, S. Mohammad, and N. Syed, "A Study of Single-Phase E-Core Hybrid Excitation Flux Switching Motor," in The Clean Energy and Technology Conference (CEAT), 2016. 
[5] J. T. Chen, Z. Q. Zhu, S. Iwasaki, and R. P. Deodhar, "A novel E-core switched-flux PM brushless AC machine," IEEE Trans. Ind. Appl., vol. 47, no. 3, pp. 1273-1282, 2011.

[6] W. Min, J. T. Chen, Z. Q. Zhu, Y. Zhu, M. Zhang, and G. H. Duan, "Optimization and Comparison of Novel E-Core and C-Core Linear Switched Flux PM Machines,” IEEE Transactions on Magnetics, vol. 47, no. 8. pp. 2134-2141, 2011.

[7] J. Liu, Y. Chen, Q. Lu, Y. Ye, and X. Huang, "Optimization and comparison of C-core and E-core linear switchedflux PM machines with odd primary poles," Electrical Machines and Systems (ICEMS), 2015 18th International Conference on. pp. 254-259, 2015.

[8] Z. Q. Zhu, J. T. Chen, Y. Pang, D. Howe, S. Iwasaki, and R. Deodhar, "Analysis of a Novel Multi-Tooth FluxSwitching PM Brushless AC Machine for High Torque Direct-Drive Applications," IEEE Transactions on Magnetics, vol. 44, no. 11.pp. 4313-4316, 2008.

[9] Z. Q. Zhu, M. Al-Ani, X. Liu, and B. Lee, "Comparison of electromagnetic performance of switched flux permanent magnet machines with mechanical flux adjusters," IET Electrical Systems in Transportation, vol. 5, no. 4. pp. 175$184,2015$.

[10] I. A. A. Afinowi, Z. Q. Zhu, D. Wu, Y. Guan, J. C. Mipo, and P. Farah, "Flux-weakening performance comparison of conventional and E-core switched-flux permanent magnet machines," Electrical Machines and Systems (ICEMS), 2014 17th International Conference on. pp. 522-528, 2014.

[11] Z. Q. Zhu, X. Liu, M. Hasegawa, A. Pride, and R. Deodhar, “COMPARATIVE STUDY OF TORQUE-SPEED CHARACTERISTICS OF ALTERNATE SWITCHED-FLUX PERMANENT MAGNET MACHINE TOPOLOGIES," vol. 10, no. c.

[12] R. Lateb, N. Takorabet, and F. Meibody-Tabar, "Effect of magnet segmentation on the cogging torque in surfacemounted permanent-magnet motors," IEEE Trans. Magn., vol. 42, no. 3, pp. 442-445, Mar. 2006.

[13] X. Liu, Z. Gu, B. Li, J. Zhao, and X. Zhang, "A novel cogging torque reduction method for the modular arc-linear flux switching permanent-magnet motor," in 2016 IEEE Conference on Electromagnetic Field Computation (CEFC), 2016, p. 1.

[14] X. Zhu, W. Hua, and M. Cheng, "Cogging torque minimization in flux-switching permanent magnet machines by tooth chamfering," in 2016 IEEE Energy Conversion Congress and Exposition (ECCE), 2016, pp. 1-7.

[15] C. Sikder, I. Husain, and W. Ouyang, "Cogging Torque Reduction in Flux-Switching Permanent-Magnet Machines by Rotor Pole Shaping," IEEE Trans. Ind. Appl., vol. 51, no. 5, pp. 3609-3619, Sep. 2015.

[16] L. Hao, M. Lin, D. Xu, W. Zhang, and N. Li, "Rotor design techniques for reducing the cogging torque in a novel dual-rotor axial field flux-switching permanent magnet machine," in 2014 17th International Conference on Electrical Machines and Systems (ICEMS), 2014, pp. 1581-1586.

[17] R. P. Deodhar, D. A. Staton, T. M. Jahns, and T. J. E. Miller, "Prediction of cogging torque using the flux-MMF diagram technique," IEEE Trans. Ind. Appl., vol. 32, no. 3, pp. 569-576, May 1996.

[18] H. Le-Huy, R. Perret, and R. Feuillet, "Minimization of Torque Ripple in Brushless DC Motor Drives," IEEE Trans. Ind. Appl., vol. IA-22, no. 4, pp. 748-755, Jul. 1986.

[19] J Abd Rani;E Sulaiman; R Kumar, "Cyclic Parameter Refinement of 4S-10P Hybrid Flux-Switching Motor for Lightweight Electric Vehicle.” Melaka, 2017.

[20] A. Saygin, "Design Optimization for Minimizing Cogging Torque in Axial Flux Permanent Magnet Machines," pp. 324-329, 2017.

[21] D. Xu, M. Lin, X. Fu, L. Hao, W. Zhang, and N. Li, "Cogging Torque Reduction of a Hybrid Axial Field FluxSwitching Permanent-Magnet Machine with Three Methods," IEEE Trans. Appl. Supercond., vol. 26, no. 4, pp. 4-8, 2016.

[22] I. Journal, F. Shafiqah, B. Universiti, T. Hussein, E. Sulaiman, U. Tun, H. Onn, M. Fairoz, O. Universiti, T. Hussein, R. Kumar, U. Tun, H. Onn, F. S. Motor, S. R. View, F. Switching, and M. View, "Cogging Torque Reduction of IPM Motor using Skewing, Notching, Pole Pairing and Rotor Pole Axial Pairing," no. May, pp. 1-7, 2017.

\section{BIOGRAPHIES OF AUTHORS}

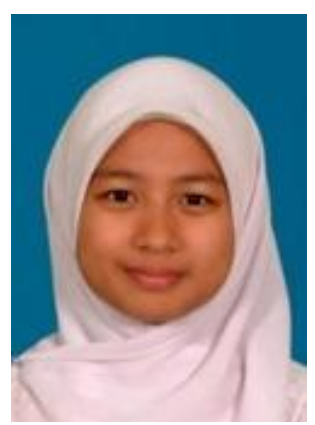

Jaudah Abd Rani was born in the capital of Johor Bahru,Johor in 1992. She received Bachelor of Electrical Engineering with Honours from Universiti Tun Hussein Onn Malaysia in 2016. In 2015, she joined Assoc. Prof. Dr. Erwan Sulaiman research team as research field assistant to study on stress analysis of E-Core hybrid excitation flux switching motor. Upon graduating her bachelor degree program, she pursue a master degree of Electrical Engineering under Assoc. Prof. Dr. Erwan Sulaiman. Her current research interests include electric machines and drive focusing on single-phase hybrid excitation flux switching motor with an E-Core stator. Jaudah is a member of Board of Engineers Malaysia. She awarded Best Presenter in a conference proceeding of 4th IET International Conference on Clean Energy. 


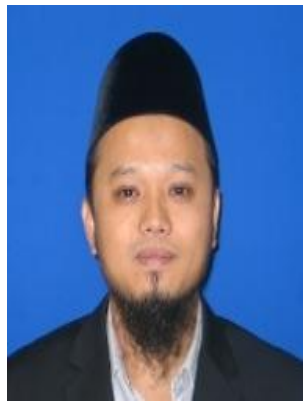

Erwan Sulaiman was born in Johor, Malaysia, on August 31, 1978. He received his B.E and M.E Degrees in Electrical Engineering from University of Malaya in 2001 and University Tun Hussein Onn Malaysia (UTHM) in 2004. He has been with UTHM from December 2004 as a lecturer. He received Doctor Degree in Electrical Engineering from Nagoya Institute of Technology (NIT), Japan in 2012. He is currently senior lecturer at Department of Electrical Power Engineering, University Tun Hussein Onn Malaysia. His research interests include design optimizations of HEFSM, FEFSM, PMFSM, in particular, for HEV drive applications.

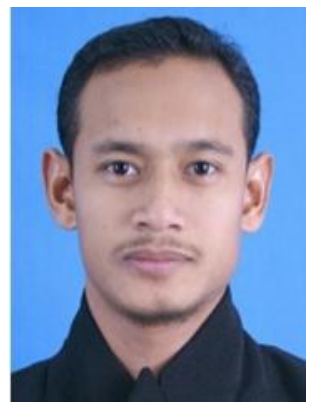

Md. Zarafi Ahmad was born in Johor, Malasyia on September 5, 1979. He received his B.E and M.E Degrees in Electrical Engineering from Universiti Teknologi Mara (UiTM) in 2004 and University Tun Hussein Onn Malaysia (UTHM) in 2007. He has been with UTHM from September 2011 as a lecturer. He received Doctor Degree in Electrical Engineering from UTHM in 2016. He is currently senior lecturer at Department of Electrical Power Engineering, UTHM. His research interests include design optimizations of outer rotor hybrid excitation flux switching machine (HEFSM) for HEV applications.

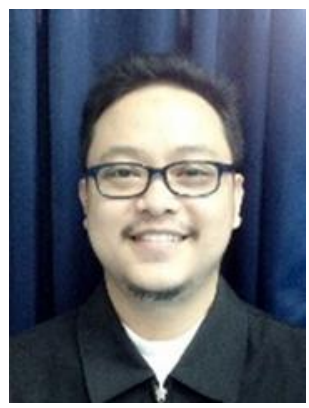

Mohd. Fairoz Omar was born in Johor, Malaysia, on May, 12, 1986. He received Diploma in Electric and Electronic Engineering from Politeknik Ibrahim Sultan in 2008. Since October 2008, he has been working under Asian Geos (M) Sdn. Bhd as Technician. He received his B.E Degree in Electronic Engineering and M.E Degree in Electrical Engineering from University Tun Hussein Onn Malaysia, in 2014 and 2016, respectively. Currently, he is Ph.D. Degree at Department of Electrical Power Engineering, University Tun Hussein Onn Malaysia. His research interests include permanent magnet flux switching machines (PMFSMs) for electric buses.

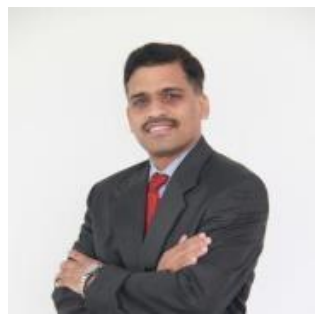

Dr. Chockalingam Aravind Vaithilingam (M'96 SM'17) born in Chennai, India, in 1975. He received the B.Engg. Degree from Bharathidasan university in 1998 , MEngg from Bharthiyar University in 2001 and the Ph.D. degree in electrical power engineering from University Putra Malaysia in 2013. From 2003 till date he worked as key researcher in the design of energy efficient and special electrical machines. Since 2011, he has been a senior lecturer with the Electrical and Electronics Engineering Department, Taylor's University, Malaysia. He is the author of five books, more than 150 indexed articles, His research interests include novel energy efficient machines for transportation and alternative energy applications. 